\title{
NEW SPECIES OF GRAMMONOTA \\ (ARANEAE, LINYPHIIDAE) FROM PANAMA AND COSTA RICA*
}

\author{
By Arthur M. Chickering \\ Museum of Comparative Zoology
}

Numerous species of the genus Grammonota Emerton, I 882, have been recognized from North and Central America as far south as Costa Rica. Two species of this genus were reported from Costa Rica by Bishop and Crosby in 1932. Kraus (1955) did not report this genus from El Salvador, and it has not been reported from Panama as far as I have been able to determine. Many specimens belonging to this genus have appeared in my collections from Panama during the past forty years and the present seems to be a convenient time to put these on record. The frequency with which members of this genus have appeared in my collections from Panama indicates, I believe, the need for more careful collecting throughout the Neotropical region.

Grants GB-I 80I and GB-5013 from the National Science Foundation have furnished aid for several collecting trips in Central America, the West Indies and Florida together with my continued research in the Museum of Comparative Zoology, Harvard University, for nearly five and one half years. As I have so frequently done in the past, I am again acknowledging the very gracious help and encouragement received from members of the staff of the Museum of Comparative Zoology extending over a period of many years.

\section{Genus Grammonota Emerton, I 882}

Grammonota tabuna sp. nov.

Figures I-IO

Holotype. The male holotype is from Gatun, Panama Canal Zone, January 30, 1958. The name of the species is an arbitrary combination of letters.

Description. Total length $\mathrm{r} .8 \mathrm{~mm}$. Carapace about $0.92 \mathrm{~mm}$ long (overlapped by anterior border of abdomen); $0.77 \mathrm{~mm}$ wide opposite second coxae where it is widest; with an obscure longitudinal thoracic groove; cephalic region considerably raised and strongly modified by a pair of conspicuous lobes (Figs. I-3); below each lobe is a

*Published with the aid of a grant from the Museum of Comparative Zoology at Harvard College. 

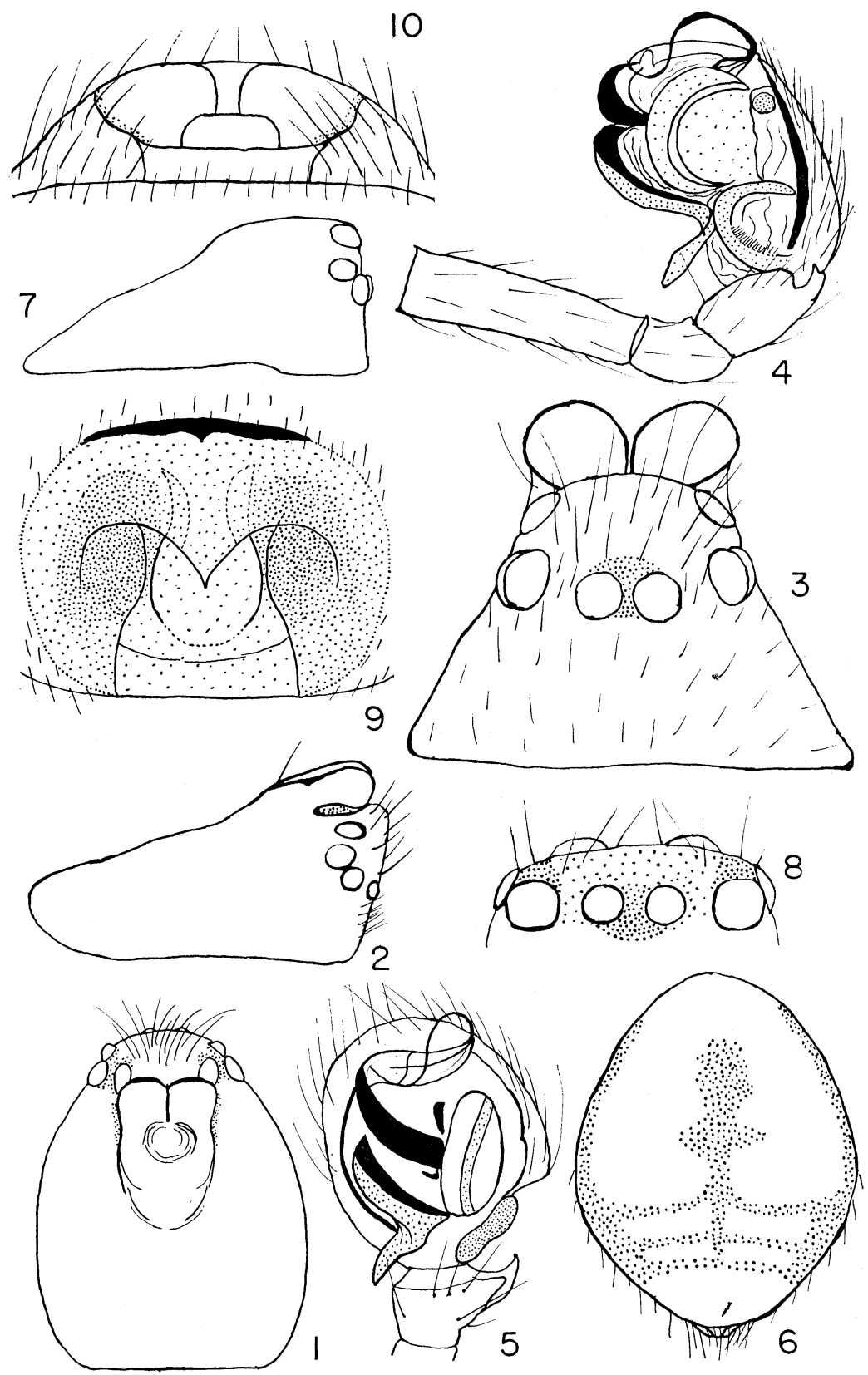
lateral pit and between the bases of the lobes there is a median dorsal depression. Eyes: eight in two rows; viewed from above, anterior row strongly recurved and posterior row only slightly so; viewed from in front, rows as shown in Figure 3. Ratio of eyes AME : ALE : PME : PLE = nearly $12:$ I2 : I4 : I3. AME narrowly separated from one another; separated from ALE by about two-thirds of their diameter. PME separated from one another by about 2.5 times their diameter; separated from PLE by less than their radius. ALE and PLE contiguous. Height of clypeus equal to slightly less than three times the diameter of AME. Chelicerae, maxillae and lip all apparently typical of the genus; cheliceral fang groove with six teeth along promargin and five along retromargin (taken from male paratype). Legs: 4I23 in order of length; true spines seem to be absent. Palp: essential features shown in Figures 4-5. Abdomen: typical of the genus; with no important modifications. Color in alcohol: carapace light yellowish-brown with variations; slightly grayish along ventral margins; with a moderate amount of black pigment in ocular area; sternum, mouth parts and legs nearly the same as the carapace with variations; sternum with a thin, grayish margin; abdomen with a median, dorsal, irregular gray stripe extending from near the base to meet three irregular, narrow, transverse bars in the posterior third; these transverse bars connect laterally with an irregular, dorsolateral stripe reaching forward nearly to the base (Fig. 6); on each side of the group of spinnerets there is a narrow gray stripe; the venter is yellowish-white. Considerable variation in color pattern has been noted among the paratypes; the gray abdominal areas may be almost lacking in some specimens.

Female paratype. Total length $2.2 \mathrm{~mm}$; carapace about $0.92 \mathrm{~mm}$ long (overlapped by anterior border of abdomen); $0.77 \mathrm{~mm}$ wide opposite second coxae where it is widest; nearly $0.33 \mathrm{~mm}$ tall (Fig. 7). Eyes: arrangement quite different than in male; viewed from above, anterior row definitely recurved and posterior row very slightly so; seen from in front, eyes essentially as shown in Figure 8. Ratio of eyes AME : ALE : PME : PLE = nearly I I :

Figures 1-10. Grammonota tabuna sp. nov. Figs. 1-2. Carapace of male holotype; from above and right lateral view, respectively. Fig. 3. Eyes and cephalic lobes of holotype from in front. Fig. 4. Left palp of holotype; retrolateral view. Fig. 5. Left palpal tarsus and tibia of holotype; ventral view. Fig. 6. Abdomen of holotype; dorsal view. Fig. 7. Carapace of female paratype; right lateral side. Fig. 8. Eyes of female paratype from in front. Figs. 9-10. Epigynum of female paratype; from below and from behind, respectively. 
16 : I5 : I5 (small irregularities in outlines make exact measurements difficult). AME separated from one another by nearly twofifths of their diameter and separated from ALE by nearly three-fifths of their diameter. PME separated from one another by slightly less than their diameter; separated from PLE by nearly one-third of their diameter; laterals contiguous to one another. Chelicerae, maxillae, lip and sternum essentially as in male. Legs : 4I23 in order of length as in male; few true spines present but with many stiff bristles. Abdomen: in general, typical of females of the genus; epigynum quite distinctive, with essential features shown in Figures 9-10. Color in alcohol: very similar to that of male but with gray areas somewhat reduced; sternum slightly grayish; abdomen as in male except that the grayish stripes on each side of the spinnerets are extended forward a short distance and somewhat widened.

Diagnosis. This species appears to be most closely related to Grammonota texana (Banks) and Grammonota gigas (Banks) but I regard it as representing a new group in the genus. Here the cephalic lobes are separated from the eyes, advanced forward and separated from the ocular region by a deep cleft. The form of the cephalic lobes, position of the eyes, features of the male palp and the female epigynum definitely establish it as a new species.

Records. The described female paratype was taken with the male holotype. The collection now contains numerous males and females from the following localities in the Panama Canal Zone: Barro Colorado Island, Gamboa, Frijoles, Madden Dam Area, Naval Station near Coccoli, Fort Clayton, Pedro Miguel, Gatun, Summit Gardens and Forest Preserve. All of these were taken during my visits to this region in 1950, I954 and 1958. In July and August, I965 I collected more than two dozen of this species in the vicinity of Turrialba, Costa Rica.

\section{Grammonota lutacola sp. nov.}

Figures II-I 5

Holotype. The female holotype is from Boquete, Panama, July, 1939. The name of the species is an arbitrary combination of letters.

Description. Total length $1.94 \mathrm{~mm}$. Carapace $0.7 \mathrm{I} \mathrm{mm}$ long; $0.55 \mathrm{~mm}$ wide opposite interval between second and third coxae where it is widest; nearly $0.22 \mathrm{~mm}$ tall; posterior declivity very gradual to posterior border; apparently with a recurved shallow depression representing the median thoracic fovea. Eyes: eight in two rows as usual; viewed from above, anterior row definitely re- 
curved and posterior row only slightly so (Fig. I I). Central ocular quadrangle only slightly wider behind than long and wider behind than in front in ratio of nearly $13:$ I 1 . Ratio of eyes AME : ALE : PME : PLE = nearly $5: 5.5: 5.5: 5$. AME separated from one another by nearly four-fifths of their diameter and from ALE by a little less than that distance. Lateral eyes contiguous. PME separated from one another by a little more than their diameter and from PLE by slightly less than their diameter. Clypeus slanted forward from AME; height nearly equal to 2.5 times the diameter of AME. Chelicerae, maxillae and lip apparently all essentially typical of females of the genus. Sternum: convex; longer than wide in ratio of nearly $7: 6$; with very narrow lateral extensions between coxae; posterior end obtusely truncated between fourth coxae which are separated by nearly five-fourths of their width. Legs: $12=43$ in order of length; with numerous slender spines. Abdomen: robust fairly typical of females of the genus; with no special modifications (Figs. I2-I3); epigynum essentially as shown in Figures I4-I5. Color in alcohol: with a rather distinctive color pattern; carapace brownish in general but with many variations; a darker, irregularly angular spot occupies the center of the dorsal area; the lateral sides are also darker; with considerable black pigment in ocular area. The sternum is a rich, dark brown; legs and mouth parts yellowish with variations. Abdomen: the ground color is light yellowish; the dorsum has a very irregular, central, brownish area (Fig. I2); there is a large, anterior, lateral brownish area (Fig. I3); nearly the whole ventral region is irregularly brownish, darker around the bases of the spinnerets. Considerable variation in the color pattern has been noted among the paratypes but the basic pattern remains in all.

Diagnosis. This species appears to be closely related to Grammonota electa Bishop and Crosby from Turrialba, Costa Rica, 1932, but this relationship must remain uncertain until the genus is much better known in the Neotropical Region.

Records. Six females are in the collection and all are from Boquete, Panama; all were taken in August I-8, I950.

\section{Grammonota dalunda sp. nov.}

Figures I6-I9

Holotype. The male holotype is from Summit Gardens, Panama Canal Zone, July 29, I954. The name of the species is an arbitrary combination of letters. 
Description. Total length $1.6 \mathrm{~mm}$. Carapace nearly $0.73 \mathrm{~mm}$ long; nearly $0.6 \mathrm{~mm}$ wide opposite second coxae where it is widest; about $0.18 \mathrm{~mm}$ tall; only slightly raised in cephalic area; median thoracic pit present but obscure; with no lobes or humps. Eyes: eight in two rows as usual in species in which the cephalic region is not modified by lobes or humps; viewed from above, posterior row straight, anterior row quite strongly recurved. Central ocular quadrangle wider behind than in front in ratio of nearly $3: 2$; slightly wider behind than long (Fig. I6). Ratio of eyes AME : ALE : PME : PLE $=7.5:$ I I : I I : 10. AME separated from one another by a little less than their diameter and from ALE by a little more than their radius; separated from PME by a little less than I.5 times their diameter. Lateral eyes contiguous. PME separated from one another by nearly four-fifths of their diameter and from PLE by a little more than their radius. Clypeus moderately porrect; height nearly equal to 3.5 times the diameter of AME. Chelicerae: vertical; parallel; typical of the genus in general; fang groove with several teeth along margins but exact number not determined because of fragility of holotype and lack of paratypes. Maxillae and lip essentially typical of the genus. Sternum: moderately convex; about as wide as long; extended just to bases of fourth coxae which are separated by a little more than their width. Legs: I 423 in order of length; with numerous long slender spines. Palp: essential features shown in Figures I7-18. Abdomen: typical of males of the genus; without special modifications. Color in alcohol: carapace light yellowish with vaguely outlined and indistinct grayish areas and with a moderate amount of black pigment in ocular area. Sternum yellowish. Legs and mouth parts light yellowish. Abdomen: yellowish with vaguely outlined, narrow, light grayish, transverse lines on dorsum and with a pale yellowish venter.

Diagnosis. This species seems to be closely related to several known species such as Grammonota suspiciosa and Grammonota nigrifrons described by Gertsch and Mulaik from Texas in 1936 and reported from Mexico in 1937 by Gertsch and Davis. I believe that the palpal features definitely establish it as a new species.

Records. The female is unknown and there are no male paratypes.

Grammonota innota sp. nov.

Figures $20-26$

Holotype. The male holotype is from Barro Colorado Island, Panama Canal Zone, February 6, 1958. The name of the species is an arbitrary combination of letters. 


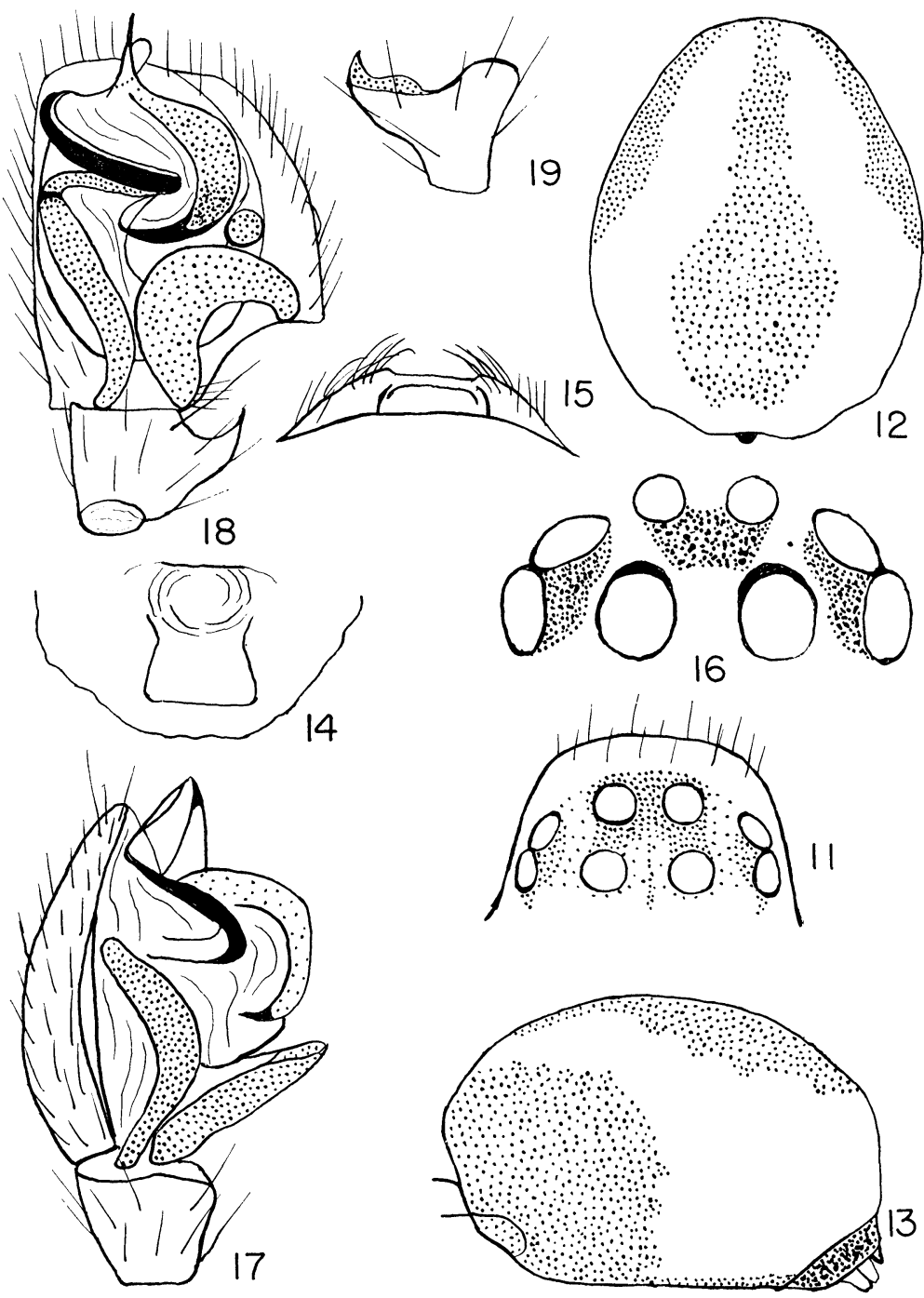

Figs. 11-15. Grammonota lutacola sp. nov. Fig. 11. Eyes of holotype from above. Figs. 12-13. Abdomen of holotype; dorsal and left lateral views, respectively. Figs. 14-15. Epigynum of holotype; from below and behind, respectively. Figs. 16-19. Grammonota dalunda sp. nov. Fig. 16. Eyes of holotype from above. Figs. 17-18. Left palpal tibia of holotype; prolateral and ventral views, respectively. Fig. 19. Left palpal tibia of holotype; dorsal view. 
Description. Total length $1.58 \mathrm{~mm}$. Carapace $0.63 \mathrm{~mm}$ long; $0.57 \mathrm{~mm}$ wide opposite second coxae where it is slightly wider than it is opposite third coxae; nearly $0.26 \mathrm{~mm}$ tall; without definite lobes or humps in cephalic area. Eyes: eight in two rows; viewed from above, anterior row gently recurved and posterior row straight (Fig. 20). Central ocular quadrangle wider behind than in front in ratio of nearly $7: 5$; slightly wider behind than long. Ratio of eyes AME : ALE : PME : PLE = nearly 8 : I I : 10 : 9.5. AME separated from one another by a little less than their diameter and from ALE by slightly more than 1.5 times their diameter. Laterals contiguous as usual. PME separated from one another by a little less than their diameter and from PLE by about six-fifths of their diameter. Height of clypeus nearly 4.5 times the diameter of AME. Chelicerae: moderately robust; vertical; parallel; fang evenly curved; fang groove probably with five small teeth along promargin and four along retromargin. Maxillae: convergent; typical of the genus. Lip: very short; twice as broad as long. Sternum: very convex; nearly as broad as long; extended between fourth coxae which are separated by their width. Legs: I 243 in order of length; long and slender as usual in the genus; with numerous slender spines. Palp: essential features shown in Figures 21-23. Abdomen: typical of males of the genus; without special modifications. Color in alcohol: carapace brown with darker streaks and vague, small, angular spots; near the middle of the dorsum there is an elongate, angular, darker spot with fine dark streaks reaching toward the posterior eyes. Legs and mouth parts yellowish brown with variations; the sternum is dark brown; abdomen brown with small light colored irregular spots. There is considerable variation in color pattern among the available paratypes.

Female paratype. Total length $\mathrm{I} .8 \mathrm{~mm}$. Carapace about $0.66 \mathrm{~mm}$ long (considerably overlapped by abdomen); o.6 I mm wide opposite second coxae where it is widest; nearly $0.26 \mathrm{~mm}$ tall. Eyes: eight as usual in females of the genus; very similar to those of male holotype. Clypeus quite porrect; height nearly equal to three times the diameter of AME. Chelicerae, maxillae and lip all essentially typical of females of the genus and without special modifications. Sternum: quite convex; about as wide as long; extended between fourth coxae which are separated by nearly I. 3 times their width. Legs : $4 \mathrm{I}=23$ in order of length; with numerous slender spines. Abdomen: typical of females of the genus in general. Epigynum: essentially as represented in Figures 24-26. Color in alcohol: considerably lighter than in the male but otherwise essentially as in that sex. The color pattern 


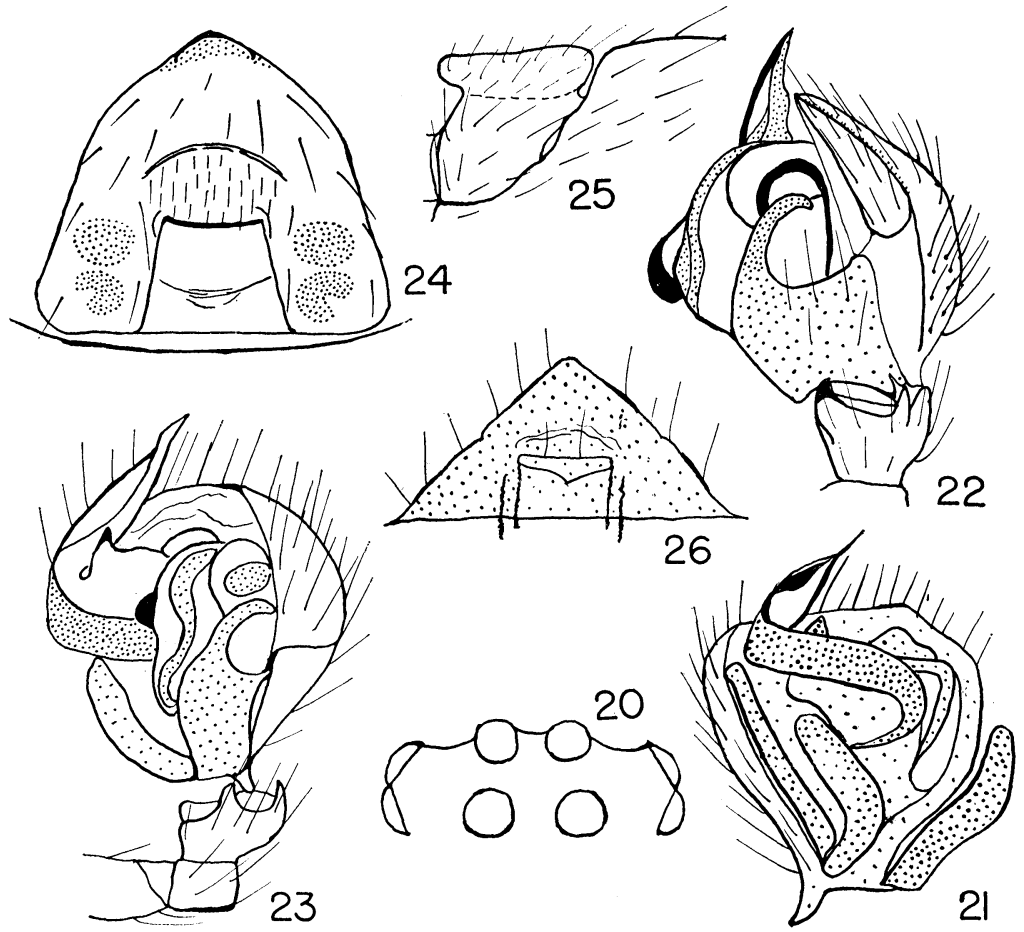

Figs. 20-26. Grammonota innota sp. nov. Fig. 20. Eyes of holotype from above. Fig. 21. Left palpal tarsus of holotype; ventral view. Figs. 22-23. Left palpal tibia and tarsus; retrolateral and ventro-retrolateral views, respectively. Fig. 24. Epigynum of female paratype from below. Fig. 25. Idem; right lateral view. Fig. 26. Idem; posterior view with posterior portion lifted; second paratype.

is quite variable among the available paratypes as was noted among the males.

Diagnosis. This species seems to be most closely related to the group of species including Grammonota suspiciosa Gertsch and Mulaik and Grammonota nigrifrons Gertsch and Mulaik described from Texas, I936 and reported from Mexico in 1937 by Gertsch and Davis.

Records. The described female paratype was taken with the holotype. Beginning in July, I934, this species has appeared in my collections during each of my seven periods of field work in the Panama 
Canal Zone ending in May, 1964. All of these have been collected on Barro Colorado Island or in the Madden Dam region.

\section{Grammonota secata sp. nov.}

Figures 27-32

Holotype. The male holotype is from Barro Colorado Island, Panama Canal Zone, January 15, 1958. The name of the species is an arbitrary combination of letters.

Description. Total length $\mathrm{r} .65 \mathrm{~mm}$. Carapace $0.73 \mathrm{~mm}$ long; $0.65 \mathrm{~mm}$ wide opposite interval between second and third coxae where it is widest; about $0.28 \mathrm{~mm}$ tall in cephalic region where it is tallest; without cephalic lobes or humps. Eyes: eight in two rows; nearly typical in general in those species without cephalic modifications; viewed from above, anterior row gently recurved and posterior row slightly procurved. Central ocular quadrangle nearly as long as wide behind; wider behind than in front in ratio of nearly i $7:$ Io. Ratio of eyes AME : ALE : PME : PLE = nearly $4: 7: 7: 7$ (long diameters always used when eyes are oval). AME separated from one another and from ALE by nearly five-eighths of their diameter. Laterals contiguous. PME separated from one another by fivesevenths of their diameter and from PLE by a little less than this distance. AME separated from PME by a little less than the diameter of the latter. Height of the clypeus slightly less than four times the diameter of AME. Chelicerae, maxillae and lip all typical of the genus and without observed modifications. Sternum: convex; slightly wider than long opposite interval between first and second coxae; extended between fourth coxae and squarely truncated; fourth coxae separated by about seven-fifths of their width. Legs: 2143 in order of length; several long, slender spines observed but exact number and placement not recorded. Palp: essential features shown in Figures 27-29. Abdomen: typical of males of the genus; with no special modifications observed. Color in alcohol: carapace light yellowish-brown with faint darker streaks; with considerable very dark brown pigment in ocular area; sternum very light grayish; legs and mouth parts yellowish with variations; palpal tarsus yellowish-brown with many variations; abdomen light yellowish in general; a narrow, indefinite, median, grayish stripe extends along the dorsum from base for about half the length of this part of the body; about five or six narrow, transverse, grayish bands cover the posterior half of the dorsum; faint grayish patches occur on the lateral sides and the 

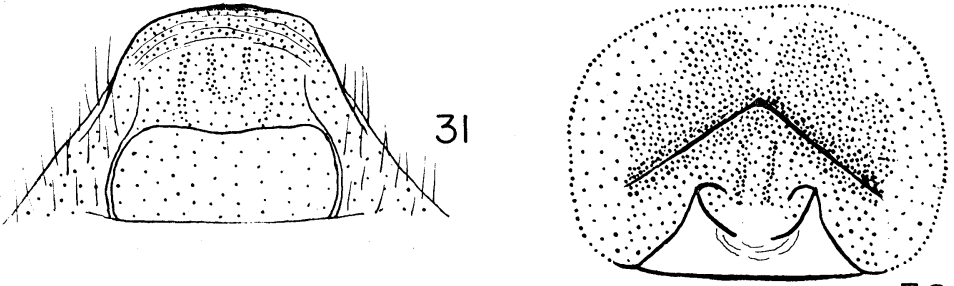

30

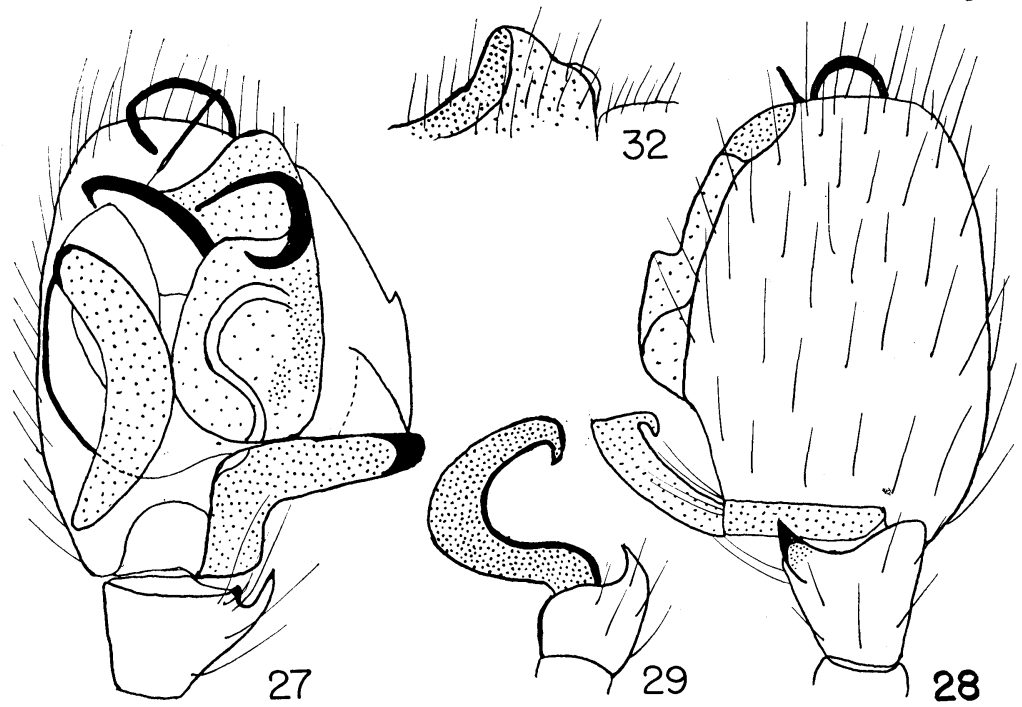

Figs. 27-32. Grammonota secata sp. nov. Figs. 27-28. Left palpal tibia and tarsus: nearly ventral and dorsal views, respectively. Fig. 29. Left palpal tibia and paracymbium; nearly retrolateral view. Figs. 30-32. Epigynum of described female paratype; from below, from behind and right lateral side, respectively. 
venter also shows small, grayish patches especially in front of the genital groove. The color pattern varies considerably among the numerous paratypes.

Female paratype. Total length I.76 mm. Carapace considerably overlapped by abdomen; very similar in general to that of male. Relationships of eyes only slightly different from those of male. Chelicerae, maxillae and lip essentially typical of females of the genus. Sternum: convex; nearly as wide as long; extended between fourth coxae which are separated by nearly four-thirds of their width. Legs also essentially as in male. Abdomen: quite typical of females of the genus. Essential features of the somewhat unusual epigynum shown in Figures 30-32. The color pattern of the described female paratype is like that of the male holotype except that the gray abdominal bands and irregular spots are somewhat clearer. The color pattern also varies considerably among the numerous female paratypes.

Diagnosis. This species seems to have the same fundamental relationships with previously known species as I have already recorded for Grammonota innota sp. nov.

Records. The described female paratype was taken in the same locality and on the same day as the male holotype. Numerous specimens of both sexes are in the collection from Barro Colorado Island, Madden Dam region, Summit Gardens, Canal Zone Forest Preserve, Summit, Pedro Miguel, and the vicinity of Paraiso all in the Panama Canal Zone. The species has been collected during my visits to this region in 1936, 1939, 1950, 1954 and 1957-1958. It seems to be quite abundant on Barro Colorado Island.

\section{Grammonota teresta sp. nov.}

Figures 33-37

Holotype. The male holotype is from Summit, Panama Canal Zone, August 23, 1950. The name of the species is an arbitrary combination of letters.

Description. Total length $1.56 \mathrm{~mm}$. Carapace $0.59 \mathrm{~mm}$ long; $0.5 \mathrm{~mm}$ wide opposite second coxae where it is widest; only about $0.13 \mathrm{~mm}$ tall; without lobes or humps on cephalic region. Eyes: eight as usual in species without cephalic lobes or humps. Viewed from above, anterior row strongly recurved, posterior row slightly so. Ratio of eyes AME : ALE : PME : PLE = nearly $3: 4$ : 4.5 : 4 . Height of clypeus nearly four times the diameter of AME. $A M E$ separated from one another by about their diameter and from ALE by slightly less than this distance. PME separated from one 


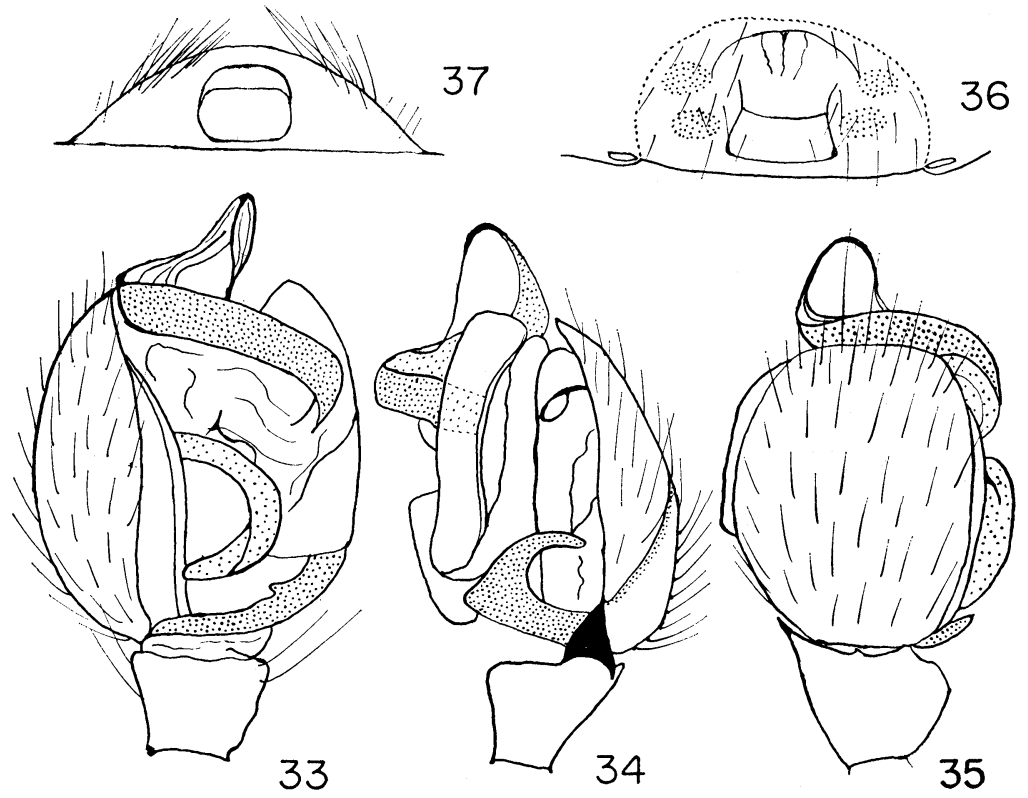

Figs. 33-37. Grammonota teresta sp. nov. Figs. 33-35. Left palpal tibia and tarsus of holotype; prolateral, retrolateral and dorsal views, respectively. Fig. 36. Epigynum of female paratype from below. 37. Idem; posterior view with posterior border lifted.

another and from PLE by slightly more than their diameter. Laterals barely separated. Chelicerae: essentially typical of males of the genus; several teeth along both margins of the fang groove but exact number difficult to determine; those on retromargin very minute and restricted to a region near the base of the fang; those on promargin relatively large and well extended along fang groove, observed on paratype male. Maxillae and lip essentially typical of the genus; lip more than twice as wide as long. Sternum: convex as usual; longer than wide in ratio of nearly $9: 8$; extended between fourth coxae which are separated by 1.2 times their width. Legs: $12=43$ in order or length; long, slender and with numerous long, slender spines. Palp: essential features shown in Figures 33-35. Abdomen: typical of the genus; without special modifications. Color in alcohol: carapace dark brown with darker radial stripes; just anterior to the thoracic pit there is a darker, irregular, central spot; eye region with considerable black pigment added to the basic brown color; sternum brown, darker along margins; legs light brownish with variations; 
coxae and trochanters whitish; palp and other mouth parts yellowishbrown with variations; abdomen brownish in general; dorsum with a broken, irregular, herringbone pattern; venter brownish with a pair of narrow, irregular, yellowish stripes widely separated.

Female paratype. Total length $\mathrm{I} .72 \mathrm{~mm}$, including somewhat extended spinnerets. Carapace about $0.66 \mathrm{~mm}$ long; $0.52 \mathrm{~mm}$ wide; otherwise essentially as in male. General features very close to those of male. Epigynum: essential features shown in Figures 36-37. Color in alcohol: essentially as in male except that there is a small, dorsal, white spot on the abdomen near the posterior end. The female paratype resembles the male so closely that a detailed description is regarded as unnecessary.

Diagnosis. This species appears to be closely related to Grammonota sclerata Ivie and Barrows apparently known only from Florida. I believe the features of the male palps and the female epigynum establish it as a new species.

Records. The described female paratype was taken with the holotype. Numerous males and females are in the collection from the following named localities in the Panama Canal Zone beginning in July, 1936; Barro Colorado Island, Forts Davis, Randolph and Sherman, Frijoles, Summit Gardens, vicinity of Paraiso, Canal Zone Forest Preserve. The species has also been collected in Panama outside of the Canal Zone in the vicinity of Arraijan, August, I936, and in the region around Boquete, August, 1936, July, 1939, and August, I954.

\section{BIBLIOGRAPHY}

Bishop, S. C. ANd C. R. Crosby

1932. Studies in American Spiders: The Genus Grammonota. Jour. New York Ent. Soc., 40: 393-421, 52 figs.

EMERTON, J. H.

1882. New England Spiders of the Family Theridiidae. Trans. Connecticut Acad., 6: 1-86.

Gertsch, W. J. and S. Mulaik

1936. New Spiders from Texas. Amer. Mus. Novitates, 863: 1-22, 4 pls.

Gertsch, W. J. and L. Irby Davis

1937. Report on a Collection of Spiders from Mexico. I. Amer. Mus. Novitates, 961: 1-29, 6 pls.

IVIE, Wilton and.W. M. BarRows

1935. Some New Spiders from Florida. Bull. Univ. Utah. 26(6) (Biol. series, 3, No. 5): 1-24, 8 pls.

Kraus, OTto

1955. Spinnen aus El Salvador (Arachnoidea, Araneae). Abhandlungen der Senckenbergischen Naturforschenden Gesellschaft, 493 : 1-112. Frankfurt am Main. 

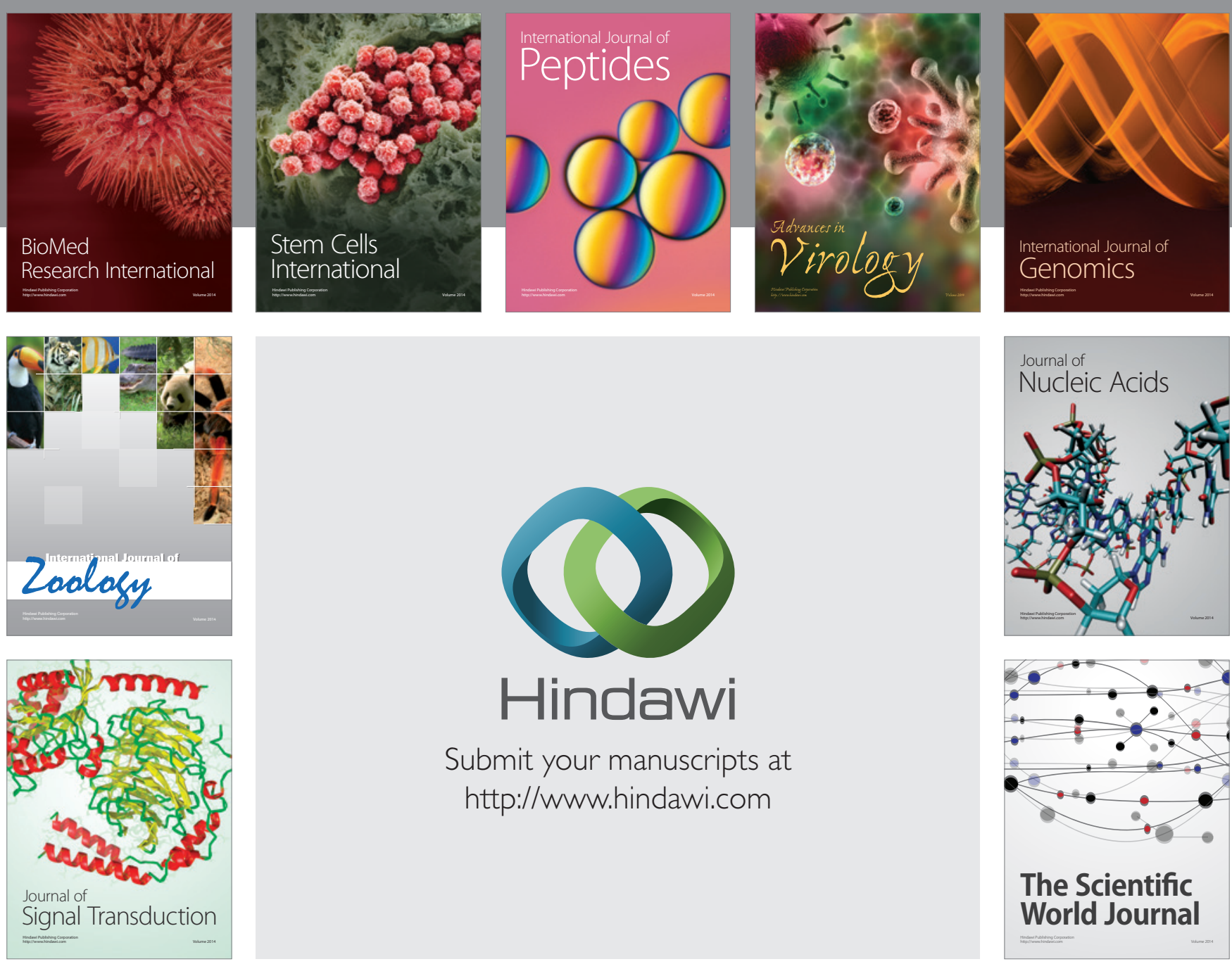

Submit your manuscripts at

http://www.hindawi.com
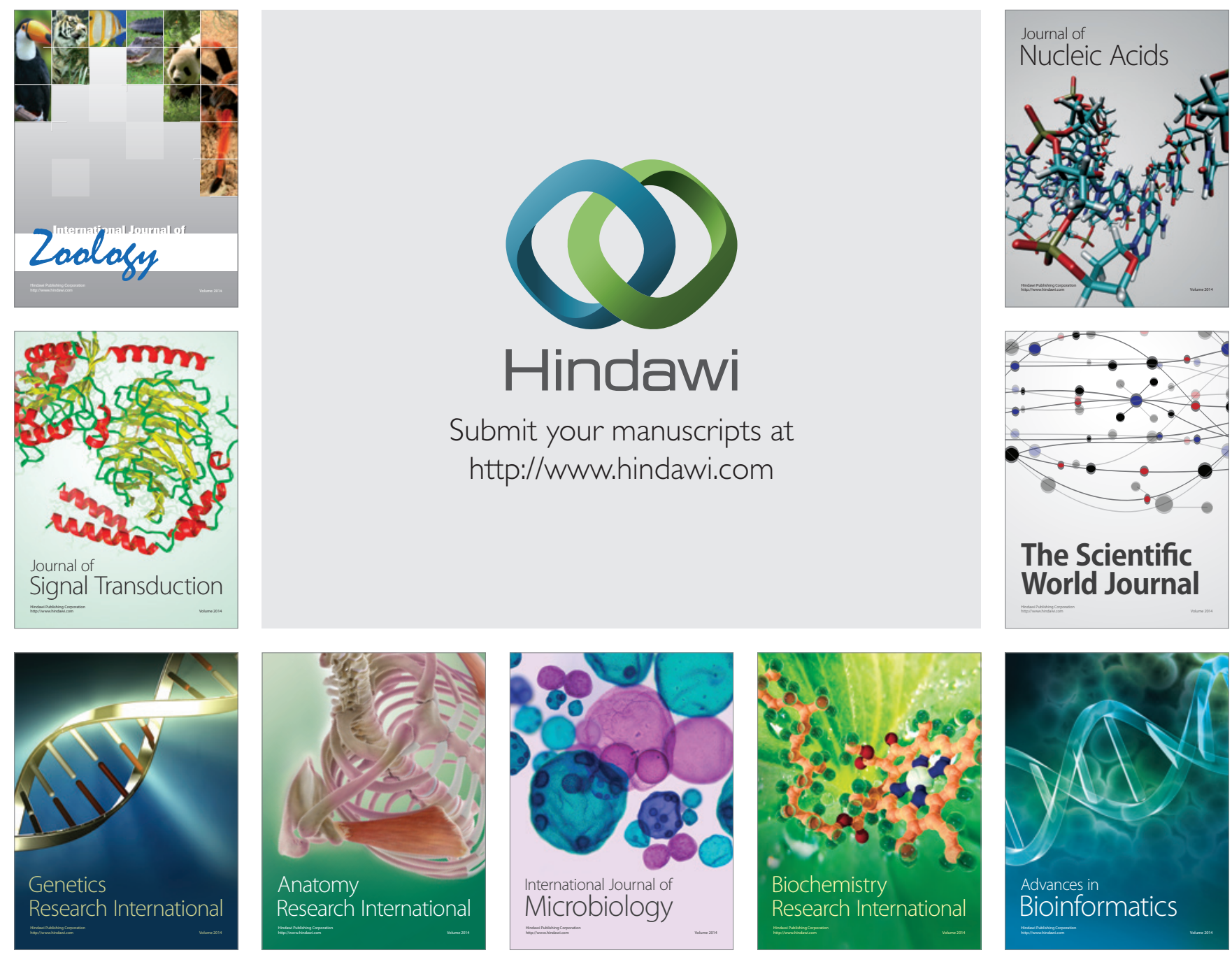

The Scientific World Journal
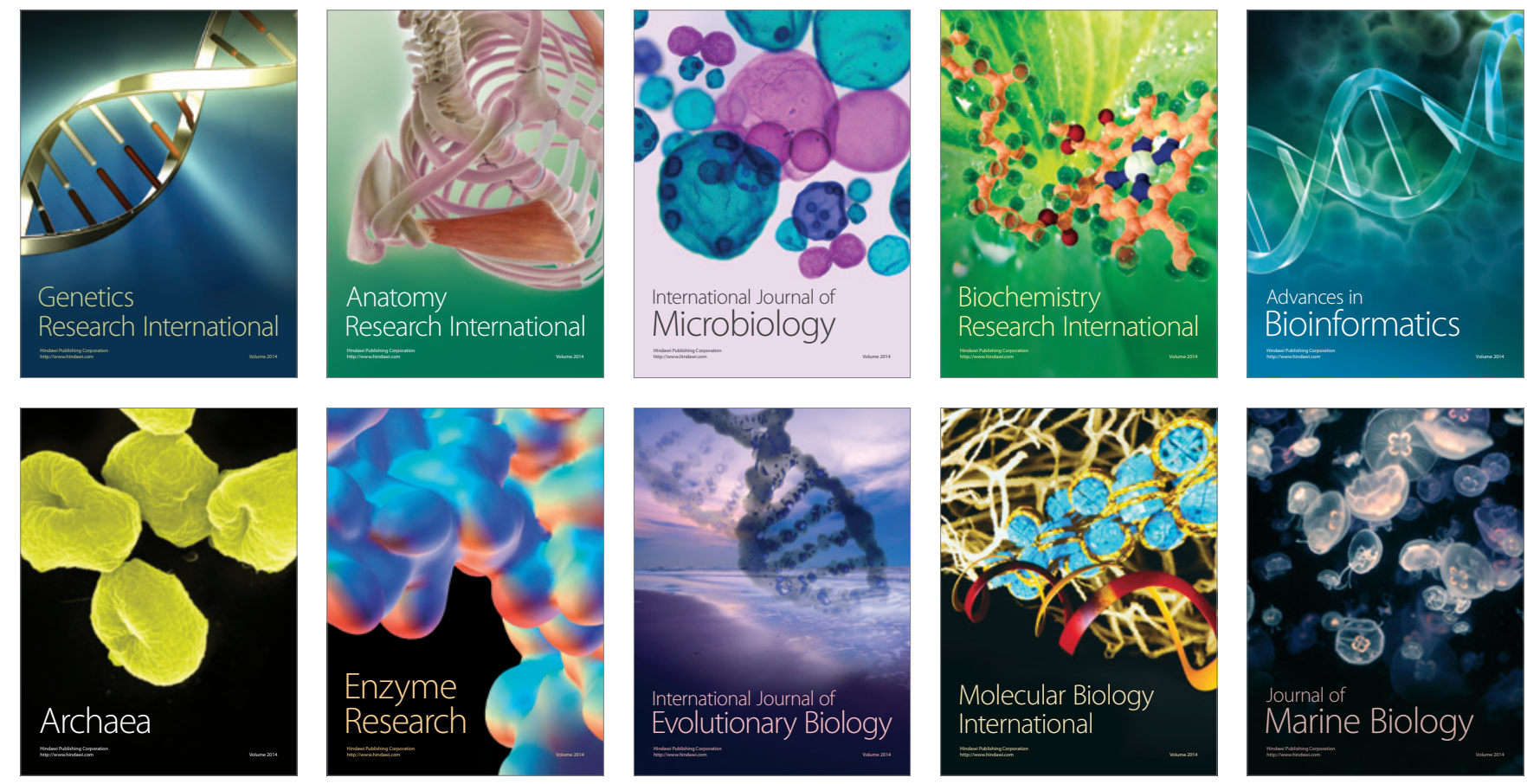